\title{
Representaciones Y Prejuicio Ettnico En El Discurso De La Prensa Chilena E Italiana'.
}

\section{Representations And Ethnic Prejudice In Chilean And Italian Press Discourse}

Mg. Claudia Milazzo', Dr. Carlos del Valle Rojas², Lic. Juan del Valle Rojas ${ }^{3}$

\begin{abstract}
1. Mg. Claudia Milazzo: Facultad de Lenguas y Literaturas Extranjeras, Universidad Alma Mater Studiorum Bolonia, Via Cartoleria, 5. claudiamil@virgilio.it

2. Dr. Carlos del Valle Rojas: Carlos Del Valle-Rojas. Periodista. Licenciado y Magister en Comunicación. Doctor en Comunicación por la Universidad de Sevilla, España. Posdoctorado en Cultura Contemporánea por la Universidad Federal de Río de Janeiro, Brasil. Investigación Posdoctoral en Comunicación por la Universidad de Oklahoma, Estados Unidos. Investiga en comunicación, interculturalidad y educación. Ha participado en más de 100 publicaciones. Investigador acreditado en CONICYT (Chile), CNPq (Brasil) y SICA (España). Ha participado en más de 20 proyectos de investigación. Académico del Departamento de Lenguas, Literatura y Comunicación y Decano de la Facultad de Educación, Ciencias Sociales y Humanidades, en la Universidad de La Frontera, Chile. carlos.delvalle@ufrontera.cl.

3. Lic. Juan del Valle Rojas; Profesor de inglés, Fundación CRESERES, dvalle1985@hotmail.com
\end{abstract}

\section{Resumen}

El artículo presenta un análisis discursivo de los textos periodísticos publicados por el diario chileno $L a$ Nación y el diario italiano La Repubblica, demostrando el rol fundamental de la prensa en expresar y divulgar el prejuicio étnico y la proliferación del racismo hacia las minorías étnicas, los inmigrantes, es decir "los otros".

Palabras claves: Inmigración, extranjero, prejuicio, estereotipo, medios de comunicación, minorías étnicas.

\begin{abstract}
This article provides a discourse analysis of journalistic texts published in the Chilean newspaper La Nacion and in the Italian newspaper La Repubblica. The analysis points out the important role of the press in order to express and disseminate the ethnic prejudice and the proliferation of racism towards the ethnic minorities, the immigrants, that is "the others".
\end{abstract}

Key words: Immigration, foreigner, prejudice, stereotype, mass media, ethnic minorities.

\footnotetext{
${ }^{1}$ Este trabajo está adscrito al proyecto financiado por el Fondo Nacional de Desarrollo Científico y Tecnológico de Chile, FONDECYT n 1120904.
} 


\section{Introducción}

En la actualidad, se ha podido observar que los medios de comunicación juegan un papel fundamental en la vida de millones de personas que consumen a diario mensajes que se elaboran sobre la base de un sistema ideológico capaz de generar, tanto en las distintas audiencias como en los profesionales de la información, un conjunto de actitudes y creencias socialmente compartidas que logran fortalecer un determinado conocimiento acerca de grupos humanos. En la sociedad, la mayoría de las personas admite que el discurso mediático moldea la percepción que se posee acerca de cómo suceden las cosas. Dicho de otra forma, ese discurso influye de una u otra forma en la visión que la gente tiene sobre la realidad social que les rodea. Esta afirmación no tiene nada de particular si pensamos que a través de los medios de comunicación obtenemos información relativa a sucesos y acontecimientos de los que resultaría complicado conseguir un conocimiento directo. Así, parece lógico suponer que los únicos datos que tengamos sobre un acontecimiento concreto condicionarán inherentemente nuestra visión del mismo.

Los medios de comunicación construyen una representación simbólica de la realidad social condicionada poderosamente por el contexto socioeconómico en el que se desarrolla su labor, puesto que antes de ser informadores, son empresas preocupadas por obtener una serie de beneficios. Desde esta perspectiva, abordar el tratamiento que el discurso periodístico da al fenómeno de la inmigración se convierte en una tarea extremadamente difícil. La inmigración es uno de los procesos sociales más importantes de nuestro tiempo. Es evidente que está transformando la sociedad actual. Pero, resulta claro que, en contra de lo que un determinado discurso sostiene, no es un fenómeno en absoluto nuevo. Todos los pueblos han desarrollado procesos migratorios con una serie de particularidades concretas. A lo largo de la historia, miles de personas han salido de sus lugares de origen para tratar de establecerse en otras regiones. Es más, se podría afirmar que todos los países que conocemos no serían lo que son sin la contribución de los diferentes grupos sociales que los procesos migratorios han puesto en contacto. La inmigración no es más que la puesta en práctica del derecho que toda persona tiene de buscar una vida mejor, a tratar de encontrar un futuro digno. A pesar de ello, la percepción que la mayoría de la gente tiene sobre este fenómeno es bien distinta.

\section{En las sociedades del denominado} primer mundo, la inmigración es vista fundamentalmente como un problema: los inmigrantes cometen delitos, no respetan nuestros valores y costumbres, su cultura les impide integrarse en las sociedades occidentales avanzadas, perjudican al mercado laboral porque trabajan a cambio de salarios ínfimos. Muchas veces los inmigrantes son vistos como una competencia desigual en el ámbito laboral, ya que están dispuestos a trabajar en cualquier tipo de labor con el fin de adquirir dinero para sustentar sus familias. Esa visión del inmigrante podría refutarse en el sentido estricto de la palabra, ya que la mayoría de las personas que hoy viven en las grandes ciudades, lo hacen a través de un proceso de inmigración de sus pueblos de origen que muchas veces son sectores rurales apartados de las grandes urbes.

Los medios de comunicación construyen a diario una representación simbólica del fenómeno de la inmigración Por lo tanto, la pregunta que representa el punto de partida de este trabajo surge por sí misma: ¿qué papel desempeñan los medios de comunicación en la percepción que la sociedad actual tiene acerca de la inmigración?

Los resultados obtenidos del análisis discursivo de los textos periodísticos publicados por el diario chileno La Nacion y el diario italiano La Repubblica, donde aparece un inmigrante, un "extranjero", un "otro", demuestran que los medios masivos son actualmente la fuente mas influyente de tendencias racistas, prejuicios y racismo (Van Dijk, 1998, 1997).

\section{Marco teórico}


El racismo es aquí definido como un sistema de dominio étnico o racial, es decir, del sistemático abuso de poder de un grupo dominante (europeo, blanco) en contra de varios grupos de tipo no-europeo- tales como minorías étnicas, inmigrantes y refugiados en Europa, las Américas y otros países eurodominados. El abuso de poder social es el ejercicio ilegítimo de poder, dando como resultado la inequidad social, e involucra el exclusivo o preferencial acceso al control sobre los escasos recursos sociales como residencia, estatus, conocimiento y respecto. El sistema de dominación étnica tiene dos dimensiones principales, concretamente: una dimensión social y una cognitiva. La dimensión social en las prácticas sociales diarias de discriminación en contra de grupos étnicamente distintos; por ejemplo, a través de la exclusión o distribución desigual de recursos sociales o derechos humanos. La dimensión cognitiva, consiste en creencias étnicas, estereotipos, prejuicios e ideología que funcionan como motivación y legitimación de tales prácticas discriminatorias. En términos muy generales, esto significa que grupos externos son representados negativamente (como diferentes, desviados o como una amenaza) comparados con el grupo interno Europeo, el cual se representa a sí mismo como superior en todos los atributos relevantes.

La mayoría de las formas de racismo hoy en día son los tipos de racismos indirecto, sutil o moderno de la vida diaria que caracterizan los muchos encuentros cotidianos por parte de grupos mayoritarios y minoritarios. Dentro el sistema del racismo, el discurso puede ser usado para problematizar, marginalizar, excluir o, de otra forma, limitar los derechos humanos de grupos étnicos externos. No todos los tipos de discurso son igualmente influyentes en la reproducción de la sociedad y de sistemas de dominación como el racismo. Obviamente los discursos públicos son más influyentes en la sociedad que los discursos privados como conversaciones diarias en familia, entre vecinos o amigos. Aquellos grupos que tienen el control de la mayoría de los discursos públicos influyentes, la elite simbólica, como políticos, periodistas, especialistas, profesores y escritores, juegan un rol especial en la reproducción del conocimiento e ideologías dominantes en la sociedad, ya que los prejuicios no son innatos, sino socialmente adquiridos, y que tal adquisición es predominantemente discursiva. Los discursos públicos de las elites simbólicas son la principal fuente de prejuicios étnicos e ideologías compartidas (Van Dijk, 1998, 1997).

Respecto al discurso racista en los medios de comunicación en Chile acerca de la población indígena, se considera desde hace mucho tiempo aquellos medios de comunicación no publican artículos que se relacionen con el racismo hacia las minorías étnicas de forma explícita, ya que hoy en día el no incluirlas se considera algo "políticamente correcto". Sin embargo, en la actualidad se les otorga otro calificativo que ya no es la condición de grupos violentos, sino que se les atribuye la condición de grupos que pretenden ocupar los territorios que ancestralmente les corresponden. Esto se refleja en la cobertura que los medios de comunicación realizan del conflicto entre el Estado chileno y las minorías étnicas, en donde es vista desde la perspectiva de los grupos violentos que luchan contra las fuerzas policiales que defienden y resguardan a sus ciudadanos. (Van Dijk, 2009).

Una de las características que, según Ramonet, distinguía al discurso de los media, era su tendencia a la "emblematización reductora de acontecimientos complejos". Este principio es particularmente relevante en el caso de la inmigración. En líneas generales, se puede afirmar que la inmensa mayoría de noticias sobre este tema se articulan en torno a dos grandes metáforas construidas por los medios de comunicación:

- la inmigración es masiva. En la actualidad los inmigrantes llegan al mundo occidental en "oleadas" difíciles de controlar;

- la inmigración es un problema. Los inmigrantes son la causa de numerosos conflictos sociales porque su cultura es difícilmente asimilable a la nuestra y, además, allí donde se asientan surge inmediatamente la delincuencia.

Una de las primeras preguntas que uno debe hacerse en un análisis crítico del discurso en general y de las noticias acerca de asuntos 
étnicos en particular, tiene relación con los tópicos del texto y conversación: "¿Sobre qué escribe o habla la gente cuando se refiere a minorías étnicas, inmigrantes, refugiados $\mathrm{u}$ "otros" étnicos en general?" Los temas de las noticias pueden ser virtualmente acerca de cualquier asunto de interés público, especialmente de las elites. Sin embargo los tópicos noticiosos sobre minorías étnicas no tienen una variación tan amplia. Por el contrario, muchos estudios han demostrado que las noticias "étnicas" se enfocan solo en algunos tópicos principales, los cuales finalmente son resumidos como "noticia problema" (Van Dijk, 1990). Inicialmente, cuando los grupos "extranjeros" comienzan a inmigrar, tal inmigración tiende a ser representada como un problema mayor, si no lo es como una invasión, y por lo tanto como una amenaza por ejemplo a nuestro bienestar, mercado de trabajo o cultura. Una vez que los inmigrantes se instalan en el país, los tópicos relevantes se enfocan de nuevo en los problemas, principalmente en problemas de recepción, alojamiento, empleo e integración.

Uno de los tópicos más frecuentes asociados con las minorías y los inmigrantes es el crimen y la violencia. Esto puede comenzar con un énfasis puesto en la inmigración y residencia "ilegal" y las actividades de la mafia, pero pronto es el tópico central para describir sus actividades en el país. El reportaje de crimen, de esta manera, generalmente se convierte en "etnizado", y formas específicas de delincuencia son típicamente atribuidas a "extranjeros", aun cuando la mayoría de dichos crímenes sean cometidos por ciudadanos nacionales. Estos son los tres tópicos principales que caracterizan a la mayoría de las noticias acerca de minorías e inmigrantes en casi todos los países.

\section{Metodología}

Para el análisis del discurso de las noticias del diario La Nación y del diario $L a$ Repubblica, se utilizó el modelo de Análisis Complejo y Crítico del Discurso (ACCD), a partir de los trabajos de Greimás y Courtés (1982) y Giroud y Panier (1988), en el marco del análisis semiótico textual, además de las ideas de J. Potter (1998), quien propone identificar las representaciones discursivas desde las factualidades reconocibles en el texto; todo lo cual ha sido re-elaborado desde una perspectiva teórico-metodológica por Del Valle (2006). La elección de ese modelo de análisis se basa en cuatro factores.

En primer lugar, el ACCD se ocupa de los problemas sociales. Su objetivo es estudiar la vertiente discursiva de los problemas sociales, es decir, estudiar cómo se reflejan en el discurso público de una determinada sociedad.

El fenómeno de la inmigración actualmente se ha convertido en uno de las principales cuestiones que preocupan a las sociedades occidentales. La inmigración es vista como un problema social que afecta a las bases mismas de nuestras sociedades tanto en los aspectos económicos como en los de índole social. En segundo lugar, el ACCD concibe las relaciones de poder como elementos discursivos. Estas relaciones de poder implican principalmente la participación de dos grupos sociales muy diferenciados: la población del país que acoge y los propios inmigrantes. En tercer lugar, el ACCD postula que el discurso constituye a la sociedad y a la cultura y viceversa. Cualquier proceso migratorio supone cambios importantes a nivel profundo dentro de una sociedad, en consecuencia, es necesario estudiar la función del discurso en este tipo de procesos pero también cómo los presupuestos culturales constituyen y definen determinados discursos públicos. Finalmente, para el ACCD el discurso realiza una labor ideológica dentro de una sociedad. En él se expresan las características ideológicas de un grupo social.

Para este trabajo fueron elegidas 4 noticias, 2 extraídas del sitio web del diario chileno La Nación y 2 del sitio web del diario italiano $\mathrm{La}$ Repubblica. Ambos medios de comunicación fueron seleccionados por su cobertura nacional y por tener una gran circulación en el propio país.

El modelo de análisis complejo y crítico del discurso utilizado en el estudio de la representación mediática procura descubrir, revelar o divulgar conexiones que a menudo se encuentran implícitas en los discursos y, en 
consecuencia, el modelo trabaja sobre manifestaciones explícitas e implícitas existentes en los textos, como es el caso de los actores, lugares simbólicos, valores temáticos, situaciones discursivas, fabricación de consensos, recorridos figurativos, lógicas de poder y matrices ideológicas.

\section{Dimensión Discursiva:}

Figuras. Las figuras son elementos de significación más o menos determinados, pero reconocibles en la lectura. Se dividen en actores, tiempo y lugares.

Recorridos Figurativos. Las figuras están dispuestas en recorridos figurativos. Esto se debe entender como el modo en que el texto utiliza las figuras y la manera como se desarrolla una figura en el texto.

Valores Temáticos. Es el sentido que se construye a partir de las relaciones entre las figuras y sus recorridos figurativos. Por lo tanto, las figuras tienen un valor a partir de su relación con otras figuras. Es la especificidad de las figuras, es decir, el papel que cumple cada una en el texto.

Situaciones Discusivas. Todo texto dispone a los actores en un(os) tiempo(s) y en un (os) lugar(es), permitiendo esta disposición la lectura de un texto a partir de la identificación de situaciones discursivas (relaciones entre figuras).

\section{Dimensión Factual:}

Discurso Empirista. “...No se limita a centrarse en los datos sino que los construye como si tuvieran una agencia propia" (Potter, 1998: 152).

Fabricación del Consenso. “...Los participantes tienden a construir corroboración cuando elaboran y socavan relatos [pues] los procedimientos para la construcción de hechos no trabajan de manera aislada. Tienen la misma probabilidad de que se recurra a ellos conjuntamente" (Potter, 1998: 152-153).

Detalles en la Narración. "Los datos específicos de una descripción, son cruciales para la actividad a la que se destina la descripción [y] son descripciones detalladas con minuciosidad" (Potter, 1998: 154).

Maximización/Minimización. "La formulación de 'casos extremos' [y] que consiste en utilizar los extremos de las dimensiones descriptivas pertinentes" (Potter, 1998: 238).

Normalización/Anormalización. “...Describir una acción que, por consenso, se considera anormal o extraña [utilizando] una organización discursiva que describe una actividad y que, al mismo tiempo, proporciona pistas para verla como anormal o extraña [por lo cual] la cuestión de la anormalidad está estrechamente vinculada con la cuestión de la regularidad" (Potter, 1998: 247-248).

\section{Resultados y discusión}

Las dos noticias del diario chileno $\mathrm{La}$ Nación tratan de hechos, en particular de crímenes donde el actor principal es un peruano, considerando que los peruanos son el mayor grupo de inmigrantes en Chile. En la primera noticia, el peruano asesina a un matrimonio donde él trabajaba. En la segunda noticia, un peruano es acusado de tráfico de droga. En ambas, el discurso periodístico sobre el extranjero es muy negativo. A través de simples frases, pero de mucho efecto, queda la imagen que el peruano, el otro, no logra integrarse al nuevo país, a las condiciones laborales, a la nueva cultura y por eso se tiene que alejarlo. Además, muchas veces en los discursos periodísticos relacionados con los inmigrantes se subraya esa "inclinación" del extranjero para la ilegalidad, los crímenes y la delincuencia. Lo mismo ocurre en el las noticias del diario italiano La Repubblica donde encontramos los rumanos. Pensando en Italia y Chile, tal vez las ideas que se tienen sobre los dos países son diferentes, son países muy distantes, con cultura e historias diferentes, pero cada sociedad intenta "defenderse del mal que llega desde afuera" e inventa enemigos externos. Así, la prensa chilena e italiana, al referirse a los inmigrantes actúa de la misma manera. De hecho, también las noticias italianas dibujan la imagen del "extranjero malo" que llega a otro país trayendo violencia, crímenes y "robando trabajo" a los nacionales. Eso es lo 
que ocurre leyendo la primera noticia donde el rumano es acusado de robo y molestias sexuales en contra de dos mujeres.

En el caso italiano, hay una excepción porque en la segunda noticia se habla positivamente de un rumano que salva la vida a un chico italiano, pero este caso es presentado como anormal. Aquí hay la llamada "anormalización" del análisis crítico del discurso. El discurso periodístico está lleno de énfasis y frases que provocan conmoción y emociones en el destinatario. El hecho es contado casi como una novela, con el fin de mostrar que existen los rumanos "buenos", aunque la mayoría son "delincuentes y violadores". Por esta razón, esa noticia es un mal intento de poner bajo una luz positiva al "otro". En la prensa, o en general en los medios de comunicación, lo "no dicho" es mucho más importante que lo "dicho", porque son los mensajes implícitos que se quedan en la mente de los destinatarios que a veces pueden actuar según esos mensajes sin darse cuenta de la razón porque lo hicieron.

El mensaje general es que los recién llegados o las minorías son por lo menos un problema, sino abiertamente una amenaza para "nosotros". Las informaciones que día a día aparecen acerca de la inmigración se adaptan perfectamente a esta tesis. En las noticias elegidas en el diario chileno La Nación y en las del italiano La Repubblica, esos tópicos se notan claramente y además adquieren más importancia por el hecho de que esos diarios tienen una gran cobertura nacional en el propio país (La Nación junto a El Mercurio y La Tercera en Chile; La Repubblica junto a Il Corriere della Sera y La Stampa en Italia).

La gran mayoría de las noticias se refieren a sucesos extraordinarios en el sentido de que se apartan de lo que se considera como cotidiano: llegada de pateras, robos o delitos protagonizados por los inmigrantes, conflictos entre ese colectivo y la población del país de acogida, etc. Los comentarios o reflexiones sobre, por ejemplo, los condicionantes socioeconómicos que están en la base de un fenómeno como la inmigración también existen pero su número es ostensiblemente menor, lo cual aporta ya un primer argumento para comprender el papel y la responsabilidad que los medios de comunicación desempeñan en la imagen que la gran mayoría de la población tiene sobre esta cuestión. El discurso mediático sobre los inmigrantes se construye básicamente sobre la noción de alteridad. "Los otros" son diferentes, distintos, tienen costumbres y modos de ver la vida muy alejados de los nuestros. Estas evidencias no supondrían ningún problema sino se presentaran casi siempre unidas a connotaciones negativas: su cultura es incompatible con la nuestra lo que genera problemas de convivencia, "el otro" aparece mayoritariamente relacionado con la delincuencia, económicamente realizan una competencia desleal a nuestros trabajadores, etc. Pero, esta figura discursiva no deja de ser una construcción del resultado de las elecciones que los medios de comunicación realizan diariamente. Este proceso simbólico se apoya en un presupuesto implícito: la homogeneidad de los grupos sociales. Por un lado, se parte de la idea de que nuestro propio grupo está claramente definido: sabemos a la perfección quién pertenece a él y quién no, qué valores y normas empleamos, qué costumbres tenemos, etc. Por otro lado, el exogrupo, en este caso los inmigrantes, también es definido como un todo uniforme: no se hacen distinciones según el lugar de procedencia, el nivel de formación o las distintas costumbres que poseen sus miembros. Así, cuando en un titular de prensa se utiliza la nacionalidad de una persona, estrategia que no responde a ningún criterio de relevancia informativa y que curiosamente casi nunca se emplea para hacer referencia a un miembro de nuestro grupo, lo que implícitamente se nos está comunicando es que en esa acción (casi siempre de tipo negativo) puede tener algo que ver la procedencia, el origen o la adscripción grupal de ese individuo. La principal característica de este proceso es el intento de construcción de una imagen positiva de nosotros y de una representación negativa del "ellos". Este principio abstracto determina gran parte de las estrategias y mecanismos lingüísticos concretos de los que a diario se sirven los medios de comunicación. En este sentido, los temas y el tratamiento de los mismos que regularmente aparecen asociados a cada una de esas figuras discursivas son bastante diferentes. Por ejemplo, cuando es un 
miembro del endogrupo el que comete un acto delictivo, una agresión a un inmigrante, nunca se hace explícita la procedencia geográfica del mismo. Sin embargo, cuando es un miembro del exogrupo el que comete ese mismo acto delictivo la nacionalidad del mismo es sistemáticamente tenida en cuenta. De la misma forma, al hacer referencia a actos relacionados con el racismo o la xenofobia cometidos por actores sociales encuadrables dentro del "nosotros", los medios de comunicación tienden a no realizar generalizaciones sobre la base de esos hechos y recalcan constantemente el carácter puntual de los mismos. Por el contrario, los delitos cometidos por miembros del exogrupo suscitan inmediatamente comentarios y reflexiones que aluden a los problemas que conlleva la presencia de ese grupo social, entendido como un todo homogéneo.

\section{Conclusiones}

La lengua nunca es neutra. Elaborar un discurso no es en absoluto concatenar un conjunto de unidades lingüísticas para referimos de una manera objetiva a la realidad social que nos rodea. Todo lo contrario, construir un discurso es básicamente adoptar un punto de vista previo desde el hablar sobre una determinada situación. El discurso mediático sobre la inmigración no es neutro. Los medios de comunicación no "informan" objetivamente acerca de esta cuestión sino que eligen un punto de vista previo que condiciona poderosamente los elementos lingüísticos que conforman sus discursos diarios. Esta perspectiva está fundamentada en la percepción de la inmigración como un problema para nuestra sociedad que implica necesariamente el surgimiento de la delincuencia y de numerosas dificultades de carácter cultural. Por lo tanto, las estructuras lingüísticas específicas empleadas cotidianamente por los medios de comunicación están marcadas por este sesgo. Por eso es importante recalcar que los medios de comunicación poseen la capacidad de alimentar estereotipos, prejuicios y, por sobre todo, actitudes discriminatorias que atentan contra personas de una cultura y nacionalidad distinta a la del colectivo dominante que pretende establecer una noción de superioridad sobre la base de un sistema de representaciones como mecanismo de exclusión y tipificación del Otro.

El discurso mediático sobre la inmigración se basa en la construcción de dos figuras simbólicas caracterizadas de muy diversa forma: el "nosotros" y el "ellos". La presentación del "ellos" se realiza desde parámetros en los que se trata de resaltar los aspectos supuestamente negativos que supone la presencia de los inmigrantes: delincuencia, falta de integración social, amenaza a nuestras costumbres, etc. El "nosotros" se construye desde una perspectiva fundamentalmente positiva: les ayudamos a integrarse y, en general, no tenemos actitudes racistas o xenófobas. Las repercusiones de todo esto son evidentes: la imagen que muchas personas tienen sobre los inmigrantes es principalmente negativa, a pesar de que en la inmensa mayoría de las ocasiones apenas han tenido un contacto directo con los mismos. El hecho de resaltar su calidad de "inmigrante" antes de comenzar con la transmisión de la información, genera un impacto negativo y de rechazo hacia la noticia por parte de los lectores, ya que asocian el impacto negativo de la noticia con la imagen mental negativa que le han hecho crear de los grupos inmigrantes. Los medios de comunicación tienen una responsabilidad insoslayable en las opiniones y actitudes claramente discriminatorias que un número cada vez mayor de ciudadanos mantiene hacia los inmigrantes.

La inmigración es una realidad noticiable por el hecho de encajar en los criterios que convierten un hecho en noticia cuando responde a la proximidad, la actualidad, la repercusión, el conflicto y la emoción que pueda generar en la audiencia. Desde estos parámetros, la representación mediática de la inmigración está impregnada de conflictividad, dramatismo y alerta. La mayoría de estudios al respecto, ponen de manifiesto el planteamiento y el carácter deshumanizante de las noticias sobre inmigración que, coincidiendo con las políticas de extranjería, se presentan en clave de cifras y no de personas, en clave de intereses económicos y no de aportaciones al país. El 
discurso de la prensa respecto a los inmigrantes obedece muchas veces a la narración de una situación negativa, sin importar el grado de culpabilidad del inmigrante, ya que obedece al carácter de "persona que no se adapta a la cultura de nuestro país", lo que se puede reflejar en la forma en la que se redacta la noticia, ya que se comienza y se enfatiza en el hecho que la persona que cometió el delito es un "extranjero de origen...".

Un ser vivo, una persona, se convierte en un "clandestino", un "ilegal", un posible problema que necesita regulaciones $y$ certificaciones, inspecciones y controles, la persona ya no existe más. Los medios de comunicación en general, presentan el fenómeno de la inmigración como un problema de seguridad y no como un problema de dignidad humana. Las imágenes y las palabras dominan y condicionan la sociedad actual, hay un "bombardeo" más o menos consciente y muchas veces no se poseen las herramientas para leer y comprender plenamente el significado de lo que se percibe. Los diarios, a través de sus informaciones, editoriales y columnas pueden moldear la opinión de los lectores en torno a cualquier tema, incluyendo la inmigración, obviamente, pero aunque no se puede negar esa capacidad de influencia, los lectores no necesariamente buscan nuevos enfoques o análisis "objetivos" sino que más bien buscan la reafirmación de los juicios e ideas que ya tienen. Son muy pocos los que deliberadamente leen opiniones encontradas sobre un mismo tema para poder sacar sus propias conclusiones.

El discurso mediático es muy rico y complejo y por eso se deben poseer habilidades de decodificación y sobretodo desarrollar el pensamiento crítico respecto a los mensajes que transmite el lenguaje mediático, para despertar una reflexión consciente, más cuidadosa y profunda. Este empuje a la reflexión sobre los métodos y las estrategias que se utilizan para crear y transmitir la información adquiere aún más importancia si pensamos en un sinnúmero de interpretaciones de la realidad que se pueden obtener según el punto de vista que se tome en cuenta. El papel que los medios de comunicación adoptan en este fenómeno resulta clave en la configuración de las corrientes de opinión y forman parte esencial del proceso de inclusión social. El papel que desempeñan es crucial a la hora de garantizar la igualdad de oportunidades o, por el contrario, perpetuar la discriminación de la población de origen extranjero. Entonces, vuelve la necesidad de desarrollar el pensamiento crítico y analítico para dominar un instrumento como los medios de comunicación y poder traer beneficios de esto sin sufrir los efectos de la homologación y distorsión de la realidad.

\section{Bibliografía}

Del Valle, C. (2006). Comunicación Participativa, Estado-Nación y Democracia. Discurso, Tecnología y Poder. Temuco: Ediciones Universidad de La Frontera.

Giroud, J.-C. y Panier, L. (1988). Semiótica. Navarra: Verbo Divino.

Greimás, A. y Courtés, J. (1982). Semiótica. Diccionario razonado de la teoría del lenguaje. Madrid: Gredos.

Potter, J. (1998). La representación de la realidad. Barcelona: Gedisa

Ramonet, I. (2003). La tiranía de la comunicación. Barcelona: Random House Mondadori.

Van Dijk, T. (2009). Dominación étnica y racismo discursivoen España y América Latina. Barcelona: Gedisa.

Van Dijk, T. (1998). Ideología. Una aproximación multidisciplinaria. Barcelona: Gedisa.

Van Dijk, T. (1997). Racismo y análisis crítico de los medios. Madrid: Paidós.

Van Dijk, T. (1990). La noticia como discurso. Madrid: Paidós. 